\title{
CADAVERIC STUDY OF BRANCHES OF ARCH OF AORTA
}

\section{Sharadkumar Pralhad Sawant *1, Shaheen Rizvi ${ }^{2}$.}

${ }^{* 1}$ Professor and Head, Department of Anatomy, K. J. Somaiya M edical College, Somaiya Ayurvihar, Eastern Express Highway, Sion, M umbai, India.

${ }^{2}$ Assistant Lecturer, Department of Anatomy, K. J. Somaiya M edical College, Somaiya Ayurvihar, Eastern Express Highway, Sion, M umbai, India.

\section{ABSTRACT}

Introduction: The aim of the study was to note the variations in the branching pattern of the Arch of Aorta. The neck and thoracic cavity was opened and structures in the superior mediastinum were dissected. The branches of the arch of aorta were traced. The embryological basis and clinical implications of variations in the branches of the Arch of aorta are discussed in detail.

M aterials and M ethods: Study was carried out in 50 donated embalmed cadavers were studied in department of Anatomy at K.J. Somaiya M edical College, Sion, M umbai. The studies were carried out in the period from December 2016 to March 2017.

Observation and Discussion: In 47 of the specimens it was observed that the arch of aorta had three branches arising from its superior surface. In 3 specimens it was noted that the arch of aorta had four branches arising from its superior surface and various other branching pattern was discussed in detail.

Conclusion: In approximately $6 \%$ of the population the left vertebral artery was seen arising from the arch of aorta, usually between left common carotid and left subclavian artery. A knowledge of a morphological variation in the branches of the Arch of aorta is considerably important for all diagnostic and surgical procedures in the head and neck region. The present study should be of significance for clinicians with regard to vascular variations in the neck and thoracic region.

KEY WORDS: Variations, Aortic Arch, Diagnostic and Surgical Procedures.

Address for Correspondence: Dr. Sharadkumar Pralhad Sawant, 25/2, Samrat Ashok Nagar Society, Shell Colony Road, Chembur, M umbai - 400 071, M aharashtra, India.

Telephone no. : 9322061220, 022-25275775, Fax no.: 022 - 24091855

E-Mail: drspsawant@gmail.com, sharad@somaiya.edu

\begin{tabular}{|c|c|c|}
\hline \multicolumn{3}{|c|}{ Access this Article online } \\
\hline \multirow{2}{*}{$\begin{array}{l}\text { Quick Response code } \\
\text { Dol: } 10.16965 / \text { ijar.2017.278 }\end{array}$} & \multicolumn{2}{|c|}{$\begin{array}{l}\text { Web site: International Journal of Anatomy and Research } \\
\text { ISSN 2321-4287 } \\
\text { www.ijmhr.org/ijar.htm }\end{array}$} \\
\hline & $\begin{array}{l}\text { Received: } 31 \text { M ay } 2017 \\
\text { Peer Review: } 01 \text { Jun } 2017 \\
\text { Revised: None }\end{array}$ & $\begin{array}{l}\text { Accepted: } 21 \text { Jun } 2017 \\
\text { Published (O): } 30 \text { Jun } 2017 \\
\text { Published (P): } 30 \text { Jun } 2017\end{array}$ \\
\hline
\end{tabular}

\section{INTRODUCTION}

The arch of aorta gives three branches, Brachiocephalic (Innominate) artery, Left common carotid artery \& Left subclavian artery. These branches supply blood to the head, face, neck and upper limb and are significant in clinical angiography. The proximal segment of these branches and the arch of aorta are frequent sites for atherosclerosis as a result of which the blood supply to brain can be compromised. Anomalies of origin and supply of these branches can alter the haemodynamics of the brain. Vertebral artery(VA) is a major branch of subclavian artery, both in origin and distribution [1].

The vertebral arteries commence at the root of 
theneck as the first branch from the supero-posterior aspect of the subclavian arteries. They lie medial to the scalenus anterior muscle. The two vertebral arteries are frequently unequal in size; the left being larger than the right. The vertebral arteries take a vertical posterior course to enter the foramina transversaria of the sixth cervical vertebrae on both sides, they then continue through the transverse foramina of the upper six cervical vertebrae [2].

Aim: To study the branches of the Arch of Aorta in order to document the frequency of anatomical variations in its branching pattern.

\section{MATERIALS AND METHODS}

50 donated embalmed cadavers ( 45 male $\& 5$ female) all ranging between age groups of 65 to 75 years were studied in department of Anatomy at K.J. Somaiya M edical College, Sion, M umbai. The studies were carried out in the period from December 2016 to M arch 2017. The neck and thoracic cavity was opened and structures in the superior mediastinum were dissected. The branches of the arch of aorta were traced.

\section{OBSERVATIONS}

In 47 of the specimens it was observed that the arch of aorta had three branches arising from its superior surface. First branch on the right side was the brachiocephalic trunk giving out its two branches - right common carotid artery and right subclavian artery. The second branch found was the left common carotid artery, the third branch was the left subclavian artery. No other congenital anomaly was found. In all the above 47 specimens, the vertebral artery originated from the posterosuperior aspect of the first part of the subclavian artery. It crossed medially in front of scalenus anterior and longus colli and behind the common carotid artery before entering the foramen transversarium of C6 vertebra.

In 3 specimens it was noted that the arch of aorta had four branches arising from its superior surface. First branch on the right side was the brachiocephalic trunk giving out its two branches- right common carotid artery and right subclavian artery. The second branch found was the left common carotid artery, the third branch was the left vertebral artery and the fourth branch was the left subclavian artery. No other congenital anomaly was found. The left vertebral artery was seen ascending behind the left common carotid artery with stellate ganglion and ventral rami of cervical spinal nerves posterior to it and thoracic duct arching anterior to it before it entered the foramen transversarium of C6 vertebra. Thereafter its course was normal. The Right VA originated from the posterosuperior aspect first part of the Right subclavian artery. It traversed medially behind the common carotid artery to enter the foramen transversarium of C6 vertebra.

In Specimen -1: The distance between the origins of left vertebral artery and the left common carotid artery was $3.56 \mathrm{~mm}$ and left vertebral artery and left subclavian artery was $4.5 \mathrm{~mm}$.

In Specimen -2: The distance between the origins of left vertebral artery and the left common carotid artery was $3.88 \mathrm{~mm}$ and left vertebral artery and left subclavian artery was $4.75 \mathrm{~mm}$.

In Specimen -3 The distance between the origins of left vertebral artery and the left common carotid artery was $3.92 \mathrm{~mm}$ and left vertebral artery and left subclavian artery was $4.46 \mathrm{~mm}$.

All photographs of the structures in the superior mediastinum were taken for proper documentation.

Fig. 1: Showing the origin of Left Vertebral Artery from Arch of Aorta between Left Common Carotid and Left Subclavian Artery in first specimen.

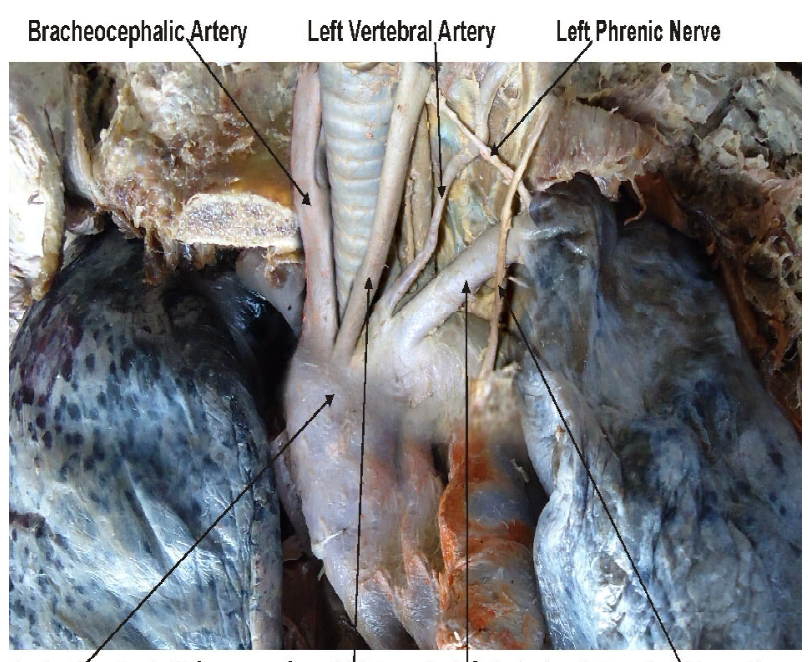

Arch of Aorta Left Common Carotid'Artery Left Subclavian Artery Leff Vagus Nerve 
Fig. 2: Showing the origin of Left Vertebral Artery from Arch of Aorta between Left Common Carotid and Left Subclavian Artery in second specimen.

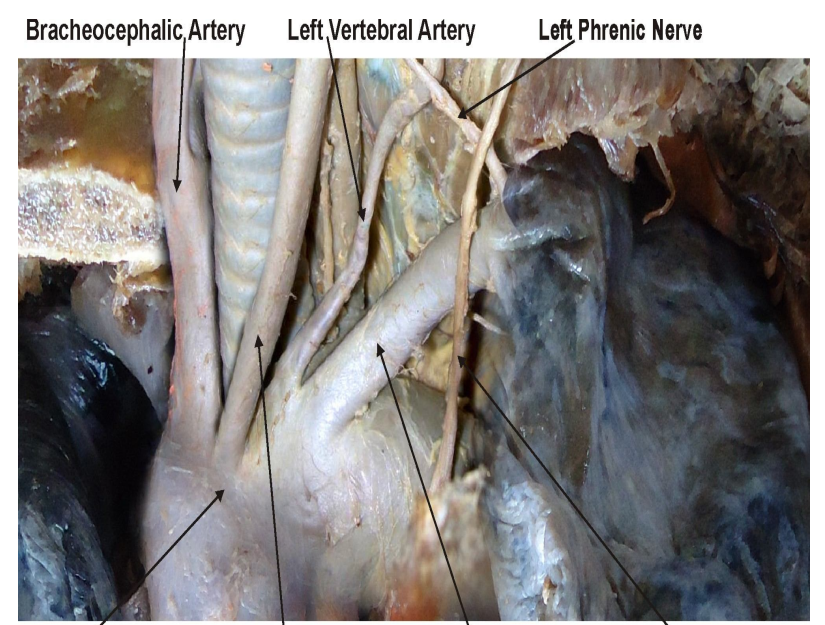

Arch of Aorta Left Common Carotid Artery Leff'Subclavian Artery Left Vagus Nerve

Fig. 3: showing the origin of Left Vertebral Artery from Arch of Aorta between Left Common Carotid and Left Subclavian Artery in third specimen.

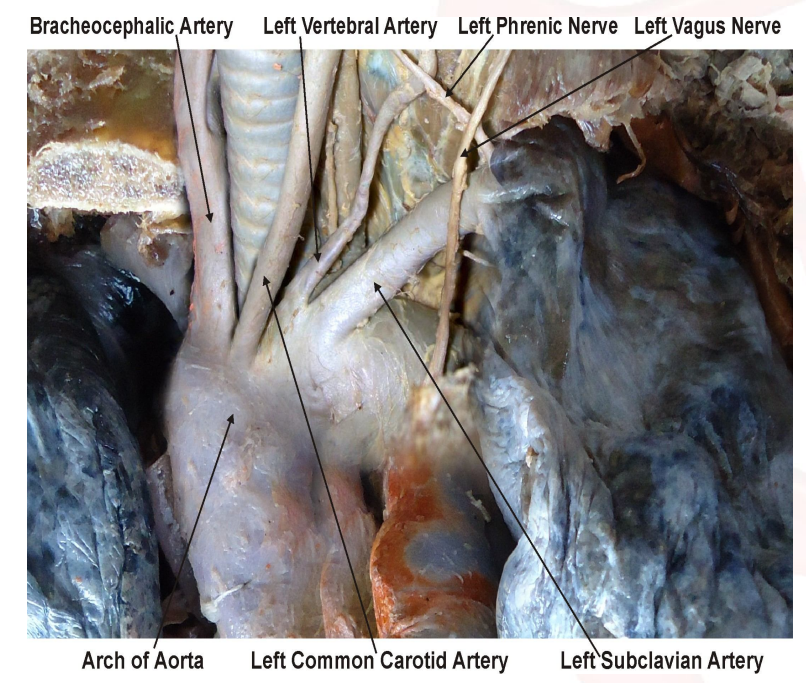

Fig. 4: Showing the normal origin of Right Vertebral artery from Right Subclavian Artery.

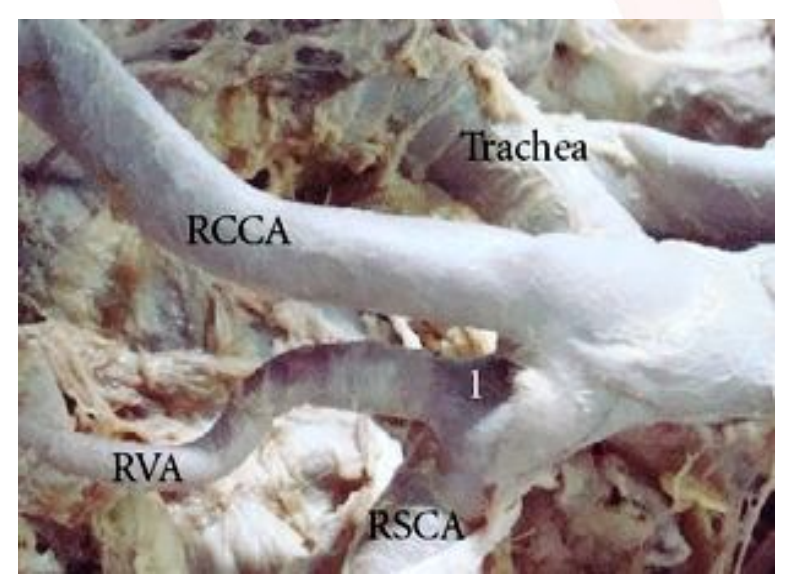

DISCUSSION

In approximately $6 \%$ of the population the left vertebral artery arises from the arch of aorta, usually between left common carotid and left subclavian artery [3]. The left vertebral artery usually enters the sixth cervical foramina transversaria (88\%), only in 5-7\% cases the left vertebral artery will enter seventh or fifth cervical vertebra [4]. Nanthan \& Seidal, 1993 had reported a left vertebral artery of aortic origin associated with retroesophageal right subclavian artery and thoracic duct terminating on right side, yet with normal origin of right vertebral artery [5]. Komiyana et al, (2001) reported the incidence of arterial dissection of the vertebral artery of aortic origin and vertebral artery of subclavian origin [6]. According to their studies left vertebral artery of aortic origin was associated with a significantly higher incidence of vertebral artery dissection than left or right vertebral artery of subclavian origin. Earlier studies by Pasturet, 1958 had reported that left vertebral artery of $<3.5 \mathrm{~mm}$ diameter may be considered hypoplastic [7].

A vertebral artery of aortic arch origin has been earlier described by different authors in the range of 3.1-8.3\% (Table I). Nevertheless, most authors have stated that it is about $2.5-3 \%$.

Table 1: Incidence of left vertebral artery of aortic arch origin [8].

\begin{tabular}{|c|l|c|}
\hline No. & \multicolumn{1}{|c|}{ Author (Year) } & Incidence (\%) \\
\hline 1 & Bean (1905) & $5.20 \%$ \\
\hline 2 & Adachi (1928) & $5.40 \%$ \\
\hline 3 & Aso (1932) & $3.20 \%$ \\
\hline 4 & M ori (1941) & $6.90 \%$ \\
\hline 5 & Stein et al. (1962) & $6 \%$ \\
\hline 6 & Argenson et al. (1980) & $5.80 \%$ \\
\hline 7 & Lippert Pab (1985) & $3.00 \%$ \\
\hline 8 & Nizanowski et al. (1982) & $3.10 \%$ \\
\hline 10 & Cavdar and Arisan (1989) & $8.30 \%$ \\
\hline 11 & Takafuji and Sato (1991) & $6.90 \%$ \\
\hline 12 & Vorster (1998) & $3.00 \%$ \\
\hline 13 & Komiyama (2001) & $2.40 \%$ \\
\hline 14 & Panicker et al. (2002) & $5 \%$ \\
\hline 15 & Yamaki (2006) & $5.80 \%$ \\
\hline
\end{tabular}

Origin point of the VA has also been reported from the thyrocervical trunk, from the brachiocephalic trunk, from the common carotid artery, from the external carotid artery, from a trunk formed by LSA and LVA [11-15].

Gluncic reported the length of the prevertebral segment of the left vertebral artery originating from aortic arch as $87.3 \mathrm{~mm}$ and its diameter at 
the origin as $3.3 \mathrm{~mm}$ [9]. Panicker reported the diameter of left vertebral artery at origin was $3.1 \mathrm{~mm}$ as compared to that of the right, which had a diameter of $6.5 \mathrm{~mm}$ at origin. The length of prevertebral segments of right vertebral artery was $38 \mathrm{~mm}$ and that of left vertebral artery was $92 \mathrm{~mm}$ [10]. Entry point of the LVA originating from the aortic arch, into the Foramen transversarium was also reported variable. M ost common entry points were reported as C5 and C6, respectively Overall, the most common entrance for vertebral arteries was at C6 [11].

Lippert Pab's classified the LVA according to the origin from the aortic arch [8] as:

\begin{tabular}{|c|c|l|}
\hline Type & Incidence & \multicolumn{1}{|c|}{ Site of Origin } \\
\hline Type A & $3 \%$ & between the LCCA and LSA \\
\hline Type B & $\triangleleft \%$ & between a common trunk formed by BT and LCCA and LSA \\
\hline Type C & $\triangleleft \%$ & after the LSA \\
\hline Type D & $\triangleleft, 1 \%$ & after the LSA as the third branch \\
\hline Type E & $\triangleleft, 1 \%$ & after a common trunk as the second branch \\
\hline Type F & $\triangleleft, 1 \%$ & RSA appears from descending aorta \\
\hline Type G & $\triangleleft \%$ & one of two roots as a penultimate branch \\
\hline Type H & $\triangleleft, 1 \%$ & both VA branch from the aortic arch \\
\hline
\end{tabular}

In the present study we got the origin of the vertebral artery from the arch of aorta in $6 \%$ of the specimens. This incidence was similar to the incidence found by Stein et al.in1962. It was more than incidence found by Bean, Adachi, Aso, Argenson et al, Lippert Pab, Nizanowski et al, Vorster et al, Komiyama, Panicker et al and Yamaki and less than found by M ori, Cavdar and Arisan and Takafuji and Sato.

Embryological Basis: Thirty or more branches of the dorsal aorta form the dorsal intersegmental arteries. They originate from the branchial aortic system. In the neck, the cervical intersegmental arteries unite to form a longitudinal artery on each side which develops into the vertebral artery. Most of the original links of the intersegmental arteries to the dorsal aorta disappear. M ostly the first part of vertebral artery develops from proximal part of dorsal branch of seventh cervical intersegmental artery proximal to postcostal anastomosis. The second part is derived from longitudinal communications of the postcostal anastomosis. Third part is from spinal branch of the first cervical intersegmental artery and fourth part is a continuation of third part [12].

Int J Anat Res 2017, 5(2.3):4024-29. ISSN 2321-4287
In the present case, the left sixth dorsal intersegmental artery may have persisted as the first part of vertebral artery hence left vertebral artery began from arch of aorta.

The left fourth aortic arch forms part of the arch of aorta. The proximal part of the arch develops from the aortic sac $\&$ the distal part from the left dorsal aorta. The left subclavian artery is not derived from aortic arch but from the left seventh intersegmental artery. As development proceeds, differential growth shifts the origin of the left subclavian artery cranially, subsequently it comes to be positioned in close proximity to the origin of the left common carotid artery [13].

According to Vorster et al, 1998, there are two factors that control the development of the branches of subclavian artery [14]. First, ability of the blood to follow the longitudinal channels offering the least resistance and second, the tension on the vessels; resulting from the caudal shifting of the heart and aorta. The proximal parts of the segmental arteries are exposed to longitudinal tension and bending due to caudal shifting of the aorta resulting in retarded blood flow and abnormal connections between longitudinal channels (vertebral artery) and subclavian artery or aorta. Panicker et al. [10], conceded the views of Vorster et al. [20], and opined that a left vertebral artery of aortic arch origin may be because of persistence of dorsal division of left 6 th intersegmental artery becoming the first part of vertebral artery instead of that of left 7th dorsal intersegmental artery.

Arey is of the view that the anomalous blood vessels may be due to (i) the choice of unusual paths in the primitive vascular plexus, (ii) the persistence of vessels normally obliterated, (iii) the disappearance of vessels normally retained, (iv) incomplete development, and (v) fusions and absorption of the parts usually distinct [15].

Clinical Significance: A knowledge of a morphological variation of the left vertebral artery is considerably important for all diagnostic and surgical procedures such as vascular angiographies and arterial dissection as well as all non-invasive procedures in the head and neck region [16]. Anomalous Vertebral Artery origin also represents a potential pitfall in diagnostic cerebrovascular injury [17]. 
An incomplete knowledge can result in complications. The extracranial portion of Vertebral Artery is frequently affected from atherosclerosis [18] and according to Fischer et al the most common site of the resultant stenosis is at its origin from subclavian artery [19]. According to Bernardi and Detori, the unusual origin of the Vertebral Artery "may favor cerebral disorders because of alterations in the cerebral haemodynamics"[20]. According to the literature, most patients with morphological variation of the left vertebral artery are clinically asymptomatic. Though the overall occurrence of anomalous origin of prevertebral segment of vertebral artery is low, it is of clinical importance to identify the origin and course of the prevertebral segment of the vertebral artery in detail so as to prevent complications [10]. Preceding any medical procedures it is vital to gauge vascularisation of the region. The most significant benefit of detecting potential left vertebral artery origin variants is diagnostic improvements before vascular surgeries of supra aortic arteries. The knowledge is essential for planning aortic arch surgery or endovascular interventions [21]. It is also of great consequence for assessing vertebro-basilar insufficiency thought to be due to atherosclerosis, and during cannulation of vertebral artery for endovascular procedures. Vitte et al. stressed to keep the variant origin of vertebral artery in mind during its manual compression which is used routinely for positional haemodynamic vertebro-basilar insufficiency [22].

\section{CONCLUSION}

In approximately $6 \%$ of the population the left vertebral artery arises from the arch of aorta, usually between left common carotid and left subclavian artery. The left vertebral artery usually enters the sixth cervical foramina transversaria (88\%), It occurs due to persistence of the left sixth dorsal intersegmental artery as the first part of vertebral artery, hence the aortic origin. A variant origin of vertebral artery of this kind may favor cerebral disorders because of alterations in cerebral haemodynamics. It is important to be aware of this rare variation in the origin and course of left vertebral artery as it might have serious implication in surgical and angiographic procedures. The knowledge is necessary and beneficial for planning aortic arch surgery or endovascular interventions.

\section{ACKNOW LEDGEM ENTS}

Authors are thankful to Dean Dr. Vinayak Sabnis Sir for his support and encouragement. Authors are also thankful to M r. M. M urugan for his help. Authors also acknowledge the immense help received from the scholars whose articles are cited and included in references of this manuscript. The authors are also grateful to authors / editors / publishers of all those articles, journals and books from where the literature for this article has been reviewed and discussed.

\section{Conflicts of Interests: None}

\section{REFERENCES}

[1]. Moore KL, Dalley AF. Clinically Oriented Anatomy. 4th Ed., Philadelphia-Baltimore-New YorkLondonBuenos Aires-Hong Kong-Sydney-Tokyo: Lippincott Williams \& Wilkins. 1999;893-894.

[2]. Hollinshead WH. Arteries: The Neck. In: Anatomy for Surgeons. Vol. I, The Head \& Neck. New York, Paul B Hoeber, Inc, M edical Book Department of Harpers \& Brothers. 1954;467-474.

[3]. Koenigsberg RA, Pereira L, Nair B, McCormick D, Schwartzman R. Unusual vertebral artery origins: examples and related pathology. Catheter Cardiovasc Interv. 2003;59:244-250.

[4]. Kubikova E, Osvaldova M, M izerakova P, El Falougy $H$, Benuska J. A variable origin of the vertebral artery. Bratisl Lek Listy. 2008;109:28-30.

[5]. Nathan H, Seidel MR. The association of a retroesophageal right subclavian artery, a rightsided terminating thoracic duct, and a left vertebral artery of aortic origin: anatomical and clinical considerations. Acta Anat (Basel). 1983;117:362-373.

[6]. Komiyana, M., Morikawa, T., Nakajiman, H., Nishikawa, M . and Yasui, T. High incidence of arterial dissection associated with left vertebral artery of aortic origin. Neurology Medical Chir (Tokyo)2001;41(1):8-11.

[7]. Pasturet, G. Traite'd anatomic humaine: appareil circutoire (tome II, fasciula 1). Paris: Massm, 1958;387-394.

[8]. Lippert H, Pabst R. Arterial Variations in Man. Classification and Frequency. JF Bergmann Verlag, Munchen. 1985;30-38.

[9]. Gluncic V, Ivkic G, Marin D, Percac S. Anomalous origin of both vertebral arteries. Clin Anat. 1999;12:281-284.

[10]. Panicker HK, Tarnekar A, Dhawane V, Ghosh SK. Anomalous origin of left vertebral artery - embryological basis and applied aspects - A case report. J Anat. Soc. India. 2002;51:234-235. 
[11]. Nayak SR, Pai M M, Prabhu LV, D'Costa S, Shetty P. Anatomical organization of aortic arch variations in the India: embryological basis and review. J Vasc Bras. 2006;5:95-100.

[12]. Keibel FN, M all FP. Development of the vascular system. In: M anual of Human Embryology. Vol II, Philadelphia and London, J. B. Lippincott Company. 1912;659-667.

[13]. Congdon ED. Transformation of the aortic arch system during during the development of human embryo. Contrib Embryol Carnegie Inst. 1922;68:47110.

[14]. Vorster W, Du Plooy PT, M eiring JH. Abnormal origin of internal thoracic and vertebral arteries. Clin Anat. 1998;11:33-37.

[15]. Arey LB. Development of arteries. The vascular system. In: Developmental Anatomy. A Textbook and Laboratory Manual of Embryology. 6th Ed., Philadelphia and London, WB Saunders Company. 1957;367-373.

[16]. Stein BM , M cCormick WF, Rodriguez JN, Taveras JM. Postmortom angiography of cerebral vascular system. Arch Neurol. 1962;7:545-559.

[17]. Goray VB, Joshi AR, Garg A, M erchant S, Yadav B, $M$ aheshwari P. Aortic arch variation: a unique case with anomalous origin of both vertebral arteries as additional branches of the aortic arch distal to left subclavian artery. AJNR Am J Neuroradiol. 2005;26: 93-95.
[18]. Vicko, G., Goran, I., Damjan, M . and Sanja, P. Anomalous origin of both vertebral arteries. Clinical Anatomy 1999;12:281-284.

[19]. Fisher CM , Gorel, Obake N, White PD. Atherosclerosis of the carotid and arteries - extracranial and intracranial. J Neuropathol Exp Neurol 1965; 24: 244-245.

[20]. Bernardi L, Dettori P. Angiographic study of a rare anomalous origin of the vertebral artery. Neuroradiology. 1975;9:43-47.

[21]. Vitte E, Feron JM , Guerin-Surville H, Koskas F. Anatomical study of digital compression of the vertebral artery at its origin at the suboccipital triangle. Anat Clin. 1985;7:77-82.

[22]. Yazar F, Yalcin B, Ozan H. Variation of the aortic arch branches: Two main trunks originating from the aortic arch. Gazi Medical Journal, 2003;14:181-184.

\section{How to cite this article: \\ Sharadkumar Pralhad Sawant, Shaheen Rizvi. CADAVERIC STUDY \\ OF BRANCHES OF ARCH OF AORTA. Int J Anat Res 2017;5(2.3):4024-4029. DOI: 10.16965/ijar.2017.278}

